\title{
Assessment of Attitudes towards Nursing Profession among Nurses and Non-Nursing Health Professionals Working in Mizan-Aman General Hospital, Southwest Ethiopia
}

\author{
Ashenafi Belete $^{1}$, Tafesse Lamaro ${ }^{1}$ and Andualem Henok ${ }^{2^{*}}$ \\ ${ }^{1}$ Department of Nursing, Mizan-Tepi University, Mizan, Ethiopia \\ ${ }^{2}$ Department of Public Health, Mizan-Tepi University, Mizan, Ethiopia \\ "Corresponding author: Andualem Henok, Department of Public Health, Mizan-Tepi University, Mizan, Ethiopia, Tel: +251910906749; E-mail: \\ andualemhenok@gmail.com
}

Rec date: Sep 08, 2015; Acc date: Oct 16, 2015; Pub date: Oct 26, 2015

Copyright: ( 2015 Belete A, et al. This is an open-access article distributed under the terms of the Creative Commons Attribution License, which permits unrestricted use, distribution, and reproduction in any medium, provided the original author and source are credited.

\begin{abstract}
Background: In Ethiopia, though, Swedish missionary nurses commenced nursing in 1895, professional growth including higher research contribution in the field of the profession was not appreciable and image for the profession is not clearer and is frustrating to those joining the profession and need to continue as career.

Objective: To assess the attitudes of nurses and non-nursing health professionals towards nursing profession among mizan-aman general hospital workers.

Method: A cross-sectional study design was carried out among health professionals working in Mizan-Aman General Hospital on their attitudes towards nursing profession. All Mizan-Aman General Hospital health professionals fulfilling the inclusion criteria were included in the study. Structured self-administered questionnaire were used to generate data and $5 \%$ of the questionnaires were pretested at health center on health professionals. The data was entered in to Epidata 3.1 and exported in to SPSS version 17 for statistical analysis.

Result: This study revealed that $64(50 \%)$ of the respondents shown favorable attitude towards nursing profession and $64(50 \%)$ shown unfavorable attitude. When percentage within a category was evaluated the majority $4(63.6 \%)$ of the physicians shown unfavorable attitude followed by the nurses $49.4 \%$ but $14(60.9 \%)$ of the nonnursing other than physicians category shown a favorable attitude. The majority, $79(61.8 \%)$ believed that nurses have important contribution to good patient outcome and13 $(10.2 \%)$ of the respondents perceived nurses working with them as incompetent.

Conclusion: Although the majority $(61.8 \%)$ of respondents believed nursing contribute to good patient outcome, only $64(50 \%)$ of them shown favorable attitude towards nursing profession. The main impact of this considerable percentage of unfavorable attitude of respondents believed to affect quality care received by patients. Therefore continuous efforts should be made so as to bring up the morale of nurses and work upon establishing respect and valuing in inter-professional relationship among the staff.
\end{abstract}

Keywords: Nurses; Attitude; Health professionals; Mizan-Aman

\section{Introduction}

Nursing emerged as a profession in the latter part of the 19th century. Historically women have been the principal caregivers of sick family members, although religious traditions such as Christianity also have contributed to the history of nursing. It was not until the 19th century however that nursing began to gain recognition as a profession. The British Nurse Florence Nightingale was instrumental in effecting this change. In 1960 she established the first scientifically based nursing training school at St. Thomas's hospital in London. This school becomes the foundation of most nursing programs throughout the western world and marked the beginning of the development of nursing through its establishment of objective criteria for determining the professional qualification [1].
There after nursing has passed through professional development patterns in different parts of the world to stand as a profession which includes; education in institutions of higher learning so as to enhance critical thinking abilities of nurses, development of its own specific body of knowledge and acceptance of the professional to deal with responsibility of providing health care needs of people [2].

Besides the key of professional autonomy, is to function independently of another profession or external force. In the developed world, the growth of professionalism in nursing has been influenced by higher and more specialized education. However, increased level of research activity; accountability and responsibility have contributed to enhance nurses' status as a profession.

As more nurses obtained baccalaureate, master's and doctoral degrees and research contributions grow the professions specific body of knowledge becomes clearer and more accurately defined [3]. A survey carried out among registered nurses in South Africa shown pay related issues dominates as the main problem at work. Improving pay 
scales and being paid according to extra experiences, responsibilities and qualification cared improve the nurses working environment [4].

In Ethiopia, though, Swedish missionary nurse's commenced nursing in 1895 Professional growth including higher research contribution in the field of the profession is not appreciable [5]. And image for the profession is not clearer and is frustrating to those joining the profession and need to continue as career. This research tries to assess attitudes of nursing and non-nursing health professionals towards this noble profession.

Many factors have influenced the way nursing is perceived by the public, by professionals, and by those who are beginning their career in nursing. Nursing is a concept that brings to mind a multiple ideas and images. These images include white uniforms, nursing caps, needles and bedpans, for others they include kindness, skills, compassion and intelligence [4]. In this era when nursing is no longer isolated in hospital or community settings, it is crucially important that the nursing professionals and other who would work with nurses have a clear meaning of the nursing profession [5].

Up to recent years, the work of nurses was poorly understood and undervalued almost everywhere and even now, when nurses are the largest number of health professions in worldwide and nursing is a key component of health care in every type of setting; many people have no idea what nursing actually does [6].

Today's health care demands teamwork from professionals and nonprofessionals. Collaborative team consisting of nurses, physicians and other health care providers developing clinical mops that define patient care needs and establish outcome measure [7]. So as one needs health care, you need nursing [8]. Thus the foundation for any team functioning is communication. It requires that all team members cooperate to establish on-going communication with each other, with the patient, and family for the role purpose of developing an integral care plan that addresses each aspect of the needed care [9].

Furthermore for effective team communication team members should have the values, recognition and discipline to the team members in particular and to their corresponding profession in general [10]. It must be realized that a nurse should be dedicated and compassionate, and resourceful. In truth, when one is a nurse of anywhere in the world he/she must have to be. How else could one instill confidence and coverage in a disabled person attempting to return to work? Since nursing is practice-oriented profession so the clinical area should attract the interest of nursing students. Study undertaken in England showed that student nurses face difficulties in becoming accepted by different staff groups each time they start a new placement in clinical areas [11]. It is important for the student to be placed in a learning environment that is accepting tolerant, understanding, considerate and flexible to the need of students. To create such environment in the clinical area, the attitude of the head nurse and the staff is very important [12]. The poor attitude was seen among nursing students. The study conducted in Bangalore showed that only $34.1 \%$ of the students agreed that they were enrolled of their own interest [13]. Although a profession is shaped into an acceptable standard through education in higher institution, and research to develop specific body of knowledge $[2,3]$ the settings in which the future nursing professionals engage in research, education and practice are becoming unwelcome. This day it is very common experience that student nurses are seen as a stranger by the clinical staffs saying, "Why do student nurses come to a hospital?" Isn't enough to be trained for three months to be a nurse", is it necessary to practice in hospital for nurses and the like. Another issue is the push of nursing professionals (nurses) to more medical roles (assigned in health center). This consequently causes most of the nurses to forget their fundamental nursing care role and rather appreciated medical roles. As Helen Scott in 2002), Editor of British Journal of nursing noted, Mr. Milburn chief Executive of NHS (National Health Service) British said "The Government will not acknowledge the nursing professions financially unless its members take on more responsibility, delegating their traditional practice and adopt more and more medical roles in order to help the government out in relation to the present shortage of doctors [14].

Experiences shown the situation in Ethiopia is the same that nurses are pushed to more medical roles at health centers and clinics meanwhile are blamed for disliking nursing care. So this brings the image that nurses are professionals who work in the absence of doctors, otherwise, a person who give injections and other routine activities. This all causes blurred image about the nursing profession autonomy and independence. These in turn causes nurses to be dissatisfied and hate their professions, and to be perceived by others as nursing not on intellectual enterprise. Therefore, it is good to question how nurses feel about their profession and attitude non-nursing health professionals have towards nursing profession.

This study enables the nurses to understand how nurses themselves perceive their own profession and see how others perceive their profession. It is also important to encourage positive attitude of nurses or non-nursing professionals towards nursing profession. On the other side it is important to increase patient satisfaction on nursing care. The study result helps to general policy makers, authorities in health care system and in particular nurses to work on bringing up nursing as a valued profession so that image of nursing will be positively changed in different professional, communities and families. Therefore this study was aimed to assess attitudes of nurses and non-nursing health professionals towards nursing profession in Mizan-Aman general hospital.

\section{Methods and Materials}

\section{Study area and period}

The study was carried out among health professionals working in Mizan-Aman general hospital from October to June 2013. MizanAman general Hospital is located in Southwest part of Ethiopia, Bench maji zone in Aman sub- town. It is 561 kilometers far from the capital city of Ethiopia, Addis Ababa. It has total staff number of 214 with 147 technical staffs and 70 supportive staffs. The hospital has emergency case team, delivery case team, outpatient case team, inpatient case team, and surgical case team.

\section{Source population}

The source population was all staffs of Mizan-Aman general hospital.

\section{Study population}

The source population was health professionals who were working in Mizan-Aman general hospital. 
Citation: Belete A, Lamaro T, Henok A (2015) Assessment of Attitudes towards Nursing Profession among Nurses and Non-Nursing Health Professionals Working in Mizan-Aman General Hospital, Southwest Ethiopia . J Nurs Care S1: 003. doi:10.4172/2167-1168.S1-003

Page 3 of 7

\section{Study design}

Institutional based cross-sectional study design was carried out among Mizan-Aman general hospital health professionals.

\section{Sample size and sampling technique}

All Health professionals of Mizan-Aman general hospital fulfilling the inclusion criteria were included in the study group.

Inclusion criteria: All health professionals who were working at Mizan-Aman general hospital for a minimum of 6 months.

Exclusion criteria: Newly arrived employees whose experience in Mizan-Aman general hospital was less than 6 months and those who work at Mizan-Aman general hospital but were not health professional.

\section{Data collection tool and method}

Pre-tested self-administered questionnaires were filled by respondents which was taken from the similar study conducted in Jimma University Specialized Hospital. The pre-testing was done at Mizan health center on $5 \%$ of health professionals. The tool consisted of three parts: Questions on socio-demographic characteristics, statements identified to nursing profession and 16 questions testing attitudes of health professionals working in Mizan-Aman general hospital .The data collectors were selected from high school students and training was given for two days that enable them to collect data. The investigators arranged convenient time for the staffs for data collection.

\section{Operational definitions}

Respondents were asked on questions which were intended to assess the attitude towards nursing profession. The questions contained both positive and negative statements. Respondents were asked whether they agree or disagree to list of positive and negative statements. Finally level of attitude was calculated as follows.

Favorable Attitude: If shown agreements to $60 \%$ of positive statements or disagree on negative statements.

Unfavorable Attitude: If shown less than 60\% agreements on positive statements or shown agreement on Negative statements.

\section{Data processing and analysis}

All filled questionnaires were checked for completeness, accuracy, clarity and consistency. Then the data was entered in to Epidata 3.1 and then exported to SPSS version 17 for statistical analysis. Frequencies were calculated. Data was presented by tables.

\section{Data quality control}

Data quality was assured by pre-testing the questionnaire before the commencement of actual data collection. Supervision was done frequently by two supervisors together with principal investigators for data quality and completeness. Each questionnaire was checked for completeness of the information collected from each subject.

\section{Ethical consideration}

Before the data collection, official letter was written from MizanTepi University, college of health sciences to ask willingness from Mizan-Aman general hospital administration as well as study participants. Study participants were also informed the privacy and confidentiality of information given by each respondent. Also they were informed that, they have all the right not to be involved in the study or not to answer any of the questions they don't want to respond. Above all ethical clearance was approved from Mizan-Tepi University.

\section{Result}

\section{Back ground and socio-demographic characters}

From 147 questionnaires distributed among Mizan-Aman general hospital health professionals 128 were returned (response rate was $87.1 \%)$. Among the participants, majority $79(61.8 \%)$ were males and the largest proportion of respondents $49(38.2 \%)$ were in age range of 26-30 years. Asked for their marital status 67 (52.34\%) reported they were married, followed by $58(45.3 \%)$ single. The majority of participants 94 (73.4\%) were diploma holders followed 28 (21.85\%) bachelor degree holder. Out of the participants 48 (37.5\%) were nonnursing health professionals other than physicians (NNOP) and nurses were $74(57.8 \%)$. The rest $(4.7 \%)$ were physicians. And most of respondents 63 (49.2\%) had a service year of 1-2 year. Asked for ward placement, $32(25 \%)$ of them reported to work at outpatient department followed by $29(22.6 \%)$ working at surgical, medical and pediatric ward. The majority of respondents 76 (59.37\%) were orthodox Christian followers (Table 1).

\begin{tabular}{|l|l|l|}
\hline Characteristics & Frequency & Percent \\
\hline Age & & \\
\hline $21-25$ & 28 & 21.9 \\
\hline $26-30$ & 49 & 38.2 \\
\hline $31-40$ & 32 & 25 \\
\hline$>40$ & 19 & 14.7 \\
\hline Sex & & \\
\hline Male & 79 & 61.8 \\
\hline Female & 49 & 38.2 \\
\hline Total & 128 & 100 \\
\hline Marital Status & & \\
\hline Single & 58 & 45.3 \\
\hline Married & 67 & 52.3 \\
\hline Divorced & 2 & 1.5 \\
\hline widowed & 1 & 0.8 \\
\hline Religion & 24.2 \\
\hline Orthodox & 76 & 1.5 \\
\hline Protestant & 31 & 73.4 \\
\hline Muslim & 94 & \\
\hline Others & & \\
\hline Educational status & & \\
\hline Diploma & & \\
\hline & & \\
\hline
\end{tabular}


Citation: Belete A, Lamaro T, Henok A (2015) Assessment of Attitudes towards Nursing Profession among Nurses and Non-Nursing Health Professionals Working in Mizan-Aman General Hospital, Southwest Ethiopia . J Nurs Care S1: 003. doi:10.4172/2167-1168.S1-003

Page 4 of 7

\begin{tabular}{|c|c|c|c|c|c|c|c|c|c|c|}
\hline \multicolumn{2}{|l|}{ BSC } & \multicolumn{2}{|l|}{28} & \multicolumn{2}{|l|}{21.9} & \multicolumn{5}{|c|}{ Ethnicity } \\
\hline \multicolumn{2}{|l|}{ MD } & & & \multicolumn{2}{|l|}{4.7} & \multicolumn{2}{|c|}{ Amhara } & \multicolumn{2}{|l|}{63} & 49.2 \\
\hline \multicolumn{2}{|l|}{ Field of study } & & & & \multicolumn{3}{|c|}{ Oromo } & \multicolumn{2}{|l|}{36} & 28.13 \\
\hline \multicolumn{2}{|l|}{ Medicine } & \multicolumn{2}{|l|}{6} & \multicolumn{2}{|l|}{4.7} & \multicolumn{2}{|c|}{ Bench } & \multicolumn{2}{|l|}{20} & 15.63 \\
\hline \multicolumn{2}{|l|}{ Nurse } & \multicolumn{2}{|l|}{74} & \multicolumn{2}{|l|}{57.9} & \multicolumn{2}{|c|}{ Others } & \multicolumn{2}{|l|}{9} & 7 \\
\hline \multicolumn{2}{|l|}{ NNOP } & \multicolumn{2}{|l|}{48} & \multicolumn{2}{|l|}{37.5} & \multirow{3}{*}{\multicolumn{5}{|c|}{$\begin{array}{l}\text { Table 1: Socio-demographic characteristic } \\
\text { Mizan-Aman general hospital, 2013. NNO } \\
\text { Physicians, OPD=Out Patient Department, }\end{array}$}} \\
\hline \multicolumn{2}{|c|}{ Ward placement } & & & & & & & & \\
\hline OPD & & 49 & & 38.2 & & & & & & \\
\hline Surgical Ward & & 10 & & 7.9 & & & & & & \\
\hline Medical Ward & & 10 & & 7.9 & & ong & dents & 64 & the & ondents shown \\
\hline Pediatrics & & 10 & & 7.9 & & rable & e. Wh & ercent & $\mathrm{a} \mathrm{ca}$ & ry was evaluated \\
\hline Maternity & & 12 & & 9.3 & & ajority & $3.6 \%)$ & te phy & own & ivorable attitude \\
\hline Pharmacy & & 5 & & 3.9 & & hysici & egory & vn a fa & titud & \\
\hline Laboratory & & 4 & & 3.1 & & $x$ & iin & od & $t c a n$ & \\
\hline Other & & 28 & & 21.9 & & 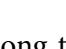 & ond & 90 & ve & contribution to \\
\hline Work Experier & & & & & & patie & ome & ery ir & and & (26.7\%) believe \\
\hline $1-2$ years & & 63 & & 49.2 & & airly & ant. $F$ & those & nts & believed nurse's \\
\hline $3-5$ years & & 33 & & 25.9 & & outior & ly imp & nt, th & ake tl & ad by $9(39.6 \%)$ \\
\hline 7-10years & & 25 & & 19.53 & & & & & & \\
\hline$>10$ years & & 7 & & 5.5 & & & & & & \\
\hline Category & Very $\mathrm{i}$ & ant & Impo & & Fairl & & Non & rtant & Tota & \\
\hline & No_ & $\%$ & No_ & $\%$ & No_ & $\%$ & No_ & $\%$ & No_ & $\%$ \\
\hline Nursing & 50 & 67.5 & 15 & 20.2 & 9 & 12.1 & - & - & 74 & 100 \\
\hline Physician & 6 & 100 & - & - & - & - & - & - & 6 & 100 \\
\hline NNOP & 23 & 47.9 & 19 & 39.5 & 6 & 12.5 & - & - & 48 & 100 \\
\hline Total & 79 & 61.8 & 34 & 26.5 & 15 & 11.8 & - & -- & 128 & 100 \\
\hline
\end{tabular}

Table 2: Distribution showing perception of respondents to contribution of nursing on patient outcome, 2013. NNOP= Non Nurses Other than Physicians

\section{Perceived competency of nurses among respondents}

Among the respondents 38 (29.7\%) described nurses working with them as competent, $77(60.2 \%)$ as fairly competent and $13(10.2 \%)$ as incompetent. Among the nurses 45 (60.8\%) of the nurses reported they believed them self that nurses working with them are fairly competent and also among asked physicians 6 (100\%), and NNOP $26(54.2 \%)$ answered similarly. From those respondents who believed nurses as incompetent, the NNOP take the first place $8(16.5 \%)$ followed by 5 $(6.8 \%)$ of the nurses (Table 3 ).

\begin{tabular}{|l|l|l|l|l|l|l|l|l|}
\hline \multirow{2}{*}{ Category } & \multicolumn{2}{|l|}{ Competent } & \multicolumn{2}{l|}{$\begin{array}{l}\text { Fairly } \\
\text { competent }\end{array}$} & \multicolumn{2}{l|}{ Incompetent } & \multicolumn{2}{l|}{ Total } \\
\cline { 2 - 8 } & No_ & $\%$ & No_ & $\%$ & No_ & $\%$ & No_ & $\%$ \\
\hline
\end{tabular}

\begin{tabular}{|l|l|l|l|l|l|l|l|l|}
\hline Nursing & 24 & 32.4 & 45 & 60.9 & 5 & 6.8 & 74 & 100 \\
\hline Physician & - & - & 6 & 100 & - & - & 6 & 100 \\
\hline NNOP & 14 & 29.1 & 26 & 54.1 & 8 & 16.7 & 48 & 100 \\
\hline Total & 38 & 29.7 & 77 & 60.1 & 13 & 10.1 & 128 & 100 \\
\hline
\end{tabular}

Table 3: Distribution showing perceptions regarding competency of nurses, 2013. NNOP= Non Nurses Other than Physicians

\section{Disciplinary measures for professional misconduct}

Among the respondents 57 (44.5\%) were taken disciplinary measures for their professional misconduct at least once during their work experience. From those reported to have been disciplined 37 
Citation: Belete A, Lamaro T, Henok A (2015) Assessment of Attitudes towards Nursing Profession among Nurses and Non-Nursing Health Professionals Working in Mizan-Aman General Hospital, Southwest Ethiopia . J Nurs Care S1: 003. doi:10.4172/2167-1168.S1-003

Page 5 of 7

(50\%) were nurse. From the disciplinary actions oral warning accounts

$42.1 \%$ followed by written warning $35.1 \%$ (Table 4 ).

\begin{tabular}{|c|c|c|c|c|c|c|c|c|c|c|c|c|}
\hline \multirow[t]{3}{*}{ Category } & \multicolumn{12}{|c|}{ Disciplinary action } \\
\hline & \multicolumn{2}{|c|}{ Financial punishment } & \multicolumn{2}{|c|}{ Oral warning } & \multicolumn{2}{|c|}{ Written warning } & \multicolumn{2}{|c|}{ work suspension } & \multicolumn{2}{|c|}{ Other } & \multicolumn{2}{|l|}{ Total } \\
\hline & No_ & $\%$ & No_ & $\%$ & No_ & $\%$ & No_ & $\%$ & No_ & $\%$ & No_ & $\%$ \\
\hline Nurses & 5 & 16.13 & 20 & 41.7 & 18 & 37.5 & 5 & 16.13 & - & - & 48 & 100 \\
\hline NNOP & 2 & 22.2 & 4 & 44.4 & 2 & 22.2 & - & - & 1 & 11.1 & 9 & 100 \\
\hline Total & 7 & 17.5 & 24 & 42.1 & 20 & 35.1 & 5 & 12.5 & 1 & 2.5 & 57 & 100 \\
\hline
\end{tabular}

Table 4: Distribution showing Disciplinary action taken due to professional misconduct on health professionals working in Mizan-Aman General hospital. NNOP= Non Nurses Other than Physicians

\section{Harassment at work area}

Among the respondents $44(34.4 \%)$ were harassed at least once during their work experience. From those who were harassed 20 $(47.7 \%)$ were nurses and $24(32.4 \%)$ were NNOP. The rest of the respondents $84(65.6 \%)$ were not harassed. The most frequent harassment reported was verbal 33 (75\%) (Table 5).

\begin{tabular}{|l|l|l|l|l|l|l|l|l|l|l|}
\hline \multirow{2}{*}{ Category } & \multicolumn{9}{|l|}{ Types of harassment } \\
\cline { 2 - 11 } & Verbal & \multicolumn{2}{l|}{ Sexual } & \multicolumn{2}{l|}{ Physical } & \multicolumn{2}{l|}{ Other } & \multicolumn{2}{l|}{ Total } \\
\cline { 2 - 11 } & No_ & $\%$ & No_ & $\%$ & No_ & $\%$ & No_ & $\%$ & No_ & $\%$ \\
\hline Nurses & 18 & 75 & - & - & 2 & 8.3 & 4 & 16.7 & 24 & 100 \\
\end{tabular}

\begin{tabular}{|l|l|l|l|l|l|l|l|l|l|l|}
\hline NNOP & 15 & 75 & - & - & 2 & 10 & 3 & 15 & 20 & 100 \\
\hline Total & 33 & 75 & - & - & 4 & 9.1 & 7 & 15.1 & 44 & 100 \\
\hline
\end{tabular}

Table 5: Distribution showing sexual harassment among respondents, 2013. NNOP=Non Nurses Other than Physicians

\section{Perceived work relationship of the respondents}

Among the respondents 39 (30.5\%) reported their work relationship as good, $36(28.1 \%)$ as excellent, $26(20.3 \%)$ as very good, $18(14.1 \%)$ as fair and $9(7.03)$ as bad. From those who rated as bad nurses took the leading point by 8 (10.8\%) followed by 1 (2.08\%) of NNOP (Table 6$)$.

\begin{tabular}{|c|c|c|c|c|c|c|c|c|c|c|c|c|}
\hline \multirow[t]{2}{*}{ Category } & \multicolumn{2}{|c|}{ Excellent } & \multicolumn{2}{|c|}{ Very good } & \multicolumn{2}{|c|}{ Good } & \multicolumn{2}{|l|}{ Fair } & \multicolumn{2}{|l|}{ Bad } & \multicolumn{2}{|l|}{ Total } \\
\hline & No_ & $\%$ & No_ & $\%$ & No_ & $\%$ & No_ & $\%$ & No_ & $\%$ & No_ & $\%$ \\
\hline Nurses & 15 & 20.3 & 18 & 24.3 & 21 & 26.2 & 12 & 16.2 & 8 & 10.8 & 74 & 100 \\
\hline Physician & 2 & 33.3 & 2 & 33.3 & 1 & 16.7 & 1 & 16.7 & - & - & 6 & 100 \\
\hline NNOP & 19 & 39.6 & 6 & 12.5 & 17 & 25.9 & 5 & 10.4 & 1 & 2.08 & 48 & 100 \\
\hline Total & 36 & 28.1 & 26 & 20.3 & 39 & 25.3 & 18 & 14.1 & 9 & 7.07 & 128 & 100 \\
\hline
\end{tabular}

Table 6: Distribution showing work relationship of respondents, 2013. NNOP=Non Nurses Other than Physicians

\section{Perceived respondents' colleagues attitude towards nursing profession}

Among the respondents 67 (52\%) perceived their colleagues have positive attitude towards nursing profession, 43 (33.6\%) a negative attitude and the other $18(14.1 \%)$ of respondents they don't know colleagues' attitude towards nursing professions. Out of the respondents who have positive attitude $50(67.6 \%)$ were nurses followed by 2 (33.3\%) physician. And 3 (50\%) of the physician believed that their colleagues have negative attitude. And 22 (45.8\%) of NNOP believed their colleagues also have negative attitude towards nursing profession.

\section{Perceived community attitude towards nursing profession}

Among the respondents $83(64.8 \%)$ believed that the community has positive attitude towards nursing professions, $26(20.3 \%)$ negative attitude and $19(14.8 \%)$ don't know the community attitude towards nursing profession. Fifty six of nurses (75.7\%), 2 (33.3\%) of physician and $25(52.1 \%)$ of NNOP believed that there is a positive attitude towards nursing profession. And 11 (14.9\%) of nurses, $3(50 \%)$ of physician and $5(10.4 \%)$ of NNOP believed that they don't know the community attitude towards nursing profession.

\section{Discussion}

Designed to assess the attitude of nurses, physician and other health professionals working in Mizan-Aman general hospital towards nursing profession, this study examined attitude and agreement of these health professionals towards nursing profession.

The response rate of this study was $87.1 \%$. From the nonrespondents, nurses accounted $4(5.12 \%)$ and physicians accounted 7(53.8\%). This might be related to work load of staffs.

Among the respondents $64(50 \%)$ of them reported to have unfavorable attitude towards nursing profession and the rest 64 (50\%) had favorable attitude. The result of this study when compared to Berharu E shows a discrepancy although the two studies lack similarity in some areas like the former study didn't included physicians and the 
respondents were post basic students; this study includes physicians and respondents who were workers (employees). Since in both cases the respondents have teamwork experience it is believed that they share common ideas on the issue of the study. This comparison showed that in the former study it was observed that $64.6 \%$ of respondents showed favorable attitude towards nursing profession whereas only $50 \%$ in this study. This discrepancy might attribute to the educational level of the respondents, where in the former study the respondents were degree (B.Sc.) students while $77.3 \%$ of respondents of this study were diploma holders. In the former study the post basic nursing students showed favorable attitude to nursing profession than the nonnursing post basic students. When attitude with in category was treated in this study, $63.6 \%$ of physicians shown unfavorable attitude and almost half of the nurses (49.4\%) shown unfavorable attitude. But $60.9 \%$ of non-nursing health professionals other than physicians were found to have unfavorable attitude.

This result showed the perception of the majority of respondents about nurses contribution to good patient out come as very important by $79(61.8 \%)$. This issue was highly denied by $34(26.56 \%)$ of NNOP, which might be as a result of their lower participation of patient care (especially for admitted patients).

Competence on one's area of expertise is a major prerequisite to harmonize inter disciplinary team work. Majority of nurses were professionally competent, but many tend to feel inadequate when they relate to inter disciplinary team. Consistent with this idea, this study revealed the majority of nurses were perceived as fairly competent by $77(60.2 \%)$ of respondents and $13(10.2 \%)$ as incompetent. All physicians and more than half of nurses believed that nurses are fairly competent. Therefore nurse perceived competence especially by the physicians and the nurse themselves; might be one of the factors for unfavorable attitude towards nursing profession.

This study also identified a report of disciplinary action for professional misconduct. It was identified that among the respondents $44.5 \%$ were disciplined for their professional misconduct at least once during their work experience, among them 37 (50\%) were nurses. This study result is partly consistent with the study conducted in USA. In the former survey it was observed that although annual complaints against physician were four fold than nurses, the average number of disciplinary actions taken was nearly the same. In the same meaning in this study no one from physician was disciplined for professional misconducts and only a few nurses were disciplined.

Conflict that exists within a team providing service in health service unit has the potential to be destructive to clinical area and professional relationship. This study showed that $39(30.5 \%)$ of respondents rated their work relationship as good, $36(28.1 \%)$ as excellent, $26(20.3 \%)$ as very good $18(14.1 \%)$ as fair and $2(4.76 \%)$ as bad. From those respondents who said badly, all of them were nurses. On the other hand asked about work area harassment $44(34.1 \%)$ were harassed by at least once during their work experience. From those who were harassed $9(37.5 \%)$ of them were nurses. This study was in consistent with that of the study done in America, it was identified that $92.5 \%$ respondents witnessed disruptive behavior by physicians and when asked to categorize the types of disruptive behavior, respondents most frequently cited yelling or raising the voice, disrespect, condescension, berating colleagues, berating patients and use of abusive language $[15,16]$.

This study also examined perception of respondents' colleagues and community towards nursing profession. The study result shows that 67
(52.3\%) and 83 (64.84\%), felt their colleagues and community respectively had positive attitude, whereas, $13(17.3 \%)$ and 17 (22.7\%) had negative attitude. The rest 48 (37.5\%) and 28 (21.9\%) don't know the attitude of their colleagues and community respectively. This study is inconsistent with that of the study done in Qatar where $57.89 \%$ felt that there was a negative community attitude towards the nursing profession [17]

\section{Limitation of the Study}

The limitations of the study were the cross-sectional nature of the study design and the small size of the study participants.

\section{Conclusion}

Although the majority (61.8\%) of respondents believed nursing contribute to good patient outcome, only 64 (50\%) of them shown favorable attitude towards nursing profession. Both nurses and other health professionals agreed that majority of the nurses working with them were fairly competent.

A significant number of participants of this study believe their colleagues have favorable attitude towards nursing profession. The overall atmosphere of nurses working environment, their professional relationship with other health professionals and the issues surrounding their work satisfaction and consequently their attitude towards their profession is not a one factor problem. Therefore improving nurses' professional satisfaction requires a multifaceted approach. The awareness of policy makers, authorities, other health professionals working with nurses, and professional organizations about issues dissatisfying nurses should be raised.

\section{References}

1. The new Encyclopedia Britannica: V (8) 15th edition 1998. By Encyclopedia Britannica, INC, USA 834-835.

2. Craven R, Hirnle C (1996) Nursing and professionalism defined Fundamentals of nursing 2nd ed. JB Lippincott company 12.

3. Demissie A (2001) Standards of Practice. The voice of nurses 1: 14.

4. Ozanic I (1961) Nursing in Ethiopia. Ethiopia nurses Association, Addis Ababa 4.

5. Dona Marie c (1992) The profession of nursing Theory, education, practices. Fundamental of nursing. 1st edition JB Lippincot company.

6. Above EY, Bish SA, Hiegnanl (1997): Nursing practice around the world: nursing (midwifery): health system development program Geneva, WHO.

7. Sullivan JE (2001) Changes in nursing Effective leadership and management in Nursing. 5th edition By prentice Hall, Inc. 5.

8. Thelma M (1990) When You Need A Health Care You Need A Nurse: American Journal of nursing 90: 1, Jan 1990: 4.

9. Team communication in health care.

10. Goode CJ, Ibarra V, Blegen MA, Anderson-Bruner J, Boshart-Yoder T, et al. (1993) What kind of recognition do staff nurses want? Am J Nurs 93: 64, 66-68.

11. Interacorp (1991) We Are Looking For Nurses Who Are A Little Of Both American journal of nursing 91: 69

12. Glossop D, Hoyles A, Lees S, Pollard C (1999) Benefits of nurse teachers returning to clinical practice. British journal of nursing 8 (6Siraw E. (2005) A study on factors contributing to clinical performance of nursing students of Jimma university..(unpublished).

13. Poreddi V, Ramachandra, Konduru R, Math SB (2012) Assessing the attitudes and perceptions towards nursing profession among nursing students. Nurs J India. Feb103: 6-8. 
Citation: Belete A, Lamaro T, Henok A (2015) Assessment of Attitudes towards Nursing Profession among Nurses and Non-Nursing Health Professionals Working in Mizan-Aman General Hospital, Southwest Ethiopia . J Nurs Care S1: 003. doi:10.4172/2167-1168.S1-003

Page 7 of 7

14. Helen Scott, George C (2002) Modernization does not mean medicalization. British Journal of nursing 11: 1228.

15. Rosenstein AH (2002) Original research: nurse-physician relationships: impact on nurse satisfaction and retention. Am J Nurs 102: 26-34.

16. Rosenstein AH, O'Daniel M (2005) Disruptive behavior and clinical outcomes: perceptions of nurses and physicians. Am J Nurs 105: 54-64.
17. Okasha MS, Ziady HH (2001) Joining the nursing profession in Qatar: motives and perceptions. East Mediterr Health J 7: 1025-1033.

This article was originally published in a special issue, entitled: "Nursing

Knowledge Development and Clinical Practice", Edited by Jolanta Lewko 